\title{
Age of Red Cells for Transfusion and Outcomes in Critically III Patients: A Meta-Analysis
}

\author{
Wei Zhang Kun Yu Ni Chen Miao Chen \\ Department of Critical Care Medicine, Affiliated Hospital of Zunyi Medical University, Zunyi, China
}

\section{Keywords}

Transfusion · Safety · Red blood cell · Mortality · Critically ill patients

\begin{abstract}
Objective: Whether the age of red blood cells (RBCs) affects mortality after transfusion in critically ill patients is controversial. Methods: We searched MEDLINE, EMBASE, PubMed, Web of Science, and the Cochrane Library Central Register of Controlled Trials databases from inception to January 10, 2018 to identify systematic reviews or meta-analyses and published randomized controlled trials of the effects of fresh versus older blood transfusion on mortality of adults in the intensive care unit (ICU). There were no date restrictions, but the language was restricted to English. The primary outcome was mortality. Risk ratios (RR) and 95\% confidence intervals (Cl) were calculated. Results: We included six trials that enrolled 8,467 critically ill patients and compared fresh RBC transfusion with current standard practice. There were no significant differences in 90-day mortality (RR 1.04, 95\% Cl 0.97, 1.12), 28/30-day mortality (RR 1.04, 95\% Cl 0.96, 1.13), in-hospital mortality (RR 1.06, 95\% Cl 0.94, 1.19), and in-ICU mortality (RR 1.11, 95\% Cl 0.97, 1.27) with fresh RBC transfusion compared with older blood transfusion. Conclusions: The study concluded that age of red cells for transfusion did not affect the outcomes in critically ill patients.
\end{abstract}

ㄷ) 2019 S. Karger AG, Basel

\section{Introduction}

Critically ill patients frequently have anemia. Moreover, anemia is present throughout the duration of the patients' intensive care unit (ICU) and hospital stay. Almost $70 \%$ of patients have a baseline hemoglobin level of $\leq 12 \mathrm{~g} / \mathrm{dL}$, and half of these have a hemoglobin level of $\leq 10 \mathrm{~g} / \mathrm{dL}$ by $48 \mathrm{~h}$ after ICU admission [1]. The pathogeny of this anemia is multifactorial, involving blood loss from diagnostic phlebotomy, intraoperative hemorrhage, and gastrointestinal bleeding, decreased iron availability, a blunted erythropoietin response, and nutritional factors $[2,3]$. Rodriguez et al. [4] found that even at an early point of critical illness (ICU day 2 or 3), most patients in the ICU had low serum ferritin (Fe) levels, total iron-binding capacity, and iron (ferrum) saturation of serum transferrin (ferritin/total iron-binding capacity). Transfusions serve as a lifesaving therapy and are also the only medical practice for treating clinical symptoms related to bleeding and anemia. Transfusions are a common therapeutic intervention among patients in the ICU, especially in older patients and those with a longer ICU stay [5-7].

Based on the "first in, first out" policy, blood banks deliver the oldest available red cell units when transfusion is requested to reduce wastage $[8,9]$. Therefore, critically ill patients may receive red blood cells (RBCs) older than 2 weeks [10]. However, during storage, a series of functional, metabolic, and biochemical changes in RBCs, including decreased $\mathrm{pH}$, increased titers of lactate and free hemoglobin, reduced concentrations of adenosine 5-triphosphate and 2,3-diphosphoglycerate, accumulation of

\section{KARGER}

(C) 2019 S. Karger AG, Basel 
extracellular potassium, membrane loss, and changes in RBC deformability over time, are collectively called storage lesion [11-13]. Accumulation of toxic substances of older RBCs may affect mortality of patients. Koch et al. [14] performed a meta-analysis of 21 studies that included 409,966 patients and showed that older blood transfusion was associated with a significantly increased risk of death [15]. In rats with anemia and myocardial infarction, transfusion of fresh (storage time $<4 \mathrm{~h}$ ) but not stored blood (storage time $<7$ days) significantly improved survival and cardiac function compared with non-transfused anemic rats [16]. This finding indirectly showed that fresh blood was superior to stored blood. Patients in the ICU are vulnerable and the severity of illness may increase their susceptibility to adverse effects of RBC storage [10]. Similarly, with transfusion of RBCs at a mean age of 16.2 days in patients in the ICU, ICU mortality and 28-day overall mortality rates were significantly higher in transfused versus non-transfused patients in an observational study [6]. Two large observational studies also showed that exposure to the maximum age of RBCs was independently associated with an increased risk of hospital death in critically ill adults $[17,18]$. However, several published, randomized controlled trials (RCTs) showed that there were no significant differences in in-hospital mortality and 90-day mortality with transfusion of fresh versus standard RBCs in critically ill patients [19-21]. A recent meta-analysis that included these RCTs indicated that patients did not benefit from fresh transfusion compared with older RBCs [22]. Dessertaine et al. [23] concluded that ICU outcomes were related to the number of leukodepleted red cells transfused, but not with their storage time. Observational trials are easily influenced by cofounders. The number and sample size of relevant RCTs were too small and important clinical differences could not be detected.

Whether the age of RBCs affects mortality after transfusion in critically ill adults remains unclear. Therefore, we performed a study to determine if fresh RBCs reduce mortality compared with standard blood in critically ill adults.

\section{Methods}

A meta-analysis of RCTs was conducted to compare fresh or short-term versus older, long-term, or standard RBC transfusion in outcomes of critically ill adults. All of the data in the study were collected from published RCTs. Therefore, informed consent of the included patients was not required for publication. Additionally, review and consent of the ethics committee were not necessary for our research. In the study, we stated that the data were available due to the fact that all of them came from the published RCTs.

Search Methods

We extracted relevant studies from MEDLINE, PubMed, EMBASE, Web of Science, and the Cochrane Central Register of Controlled Trials databases. The MeSH terms "blood", "erythrocyte*", "red cell*”, "red blood cell*”, "RBC", "whole blood", "erythrocyte transfusion”, “transfusion”, “age”, “aged”, “aging”, “fresh*”, “old”, "older", "new”, "newer", "young”, "store*”, "storage”, "storing”, and "preserve*" were used. There were no date restrictions, but the language was restricted to English. The search was restricted to systematic reviews, reviews, or meta-analyses, including RCTs. Another search was performed to identify published RCTs at any time using the same keywords as above. The population only involved critically ill adults. These searches were updated in January 10,2018 , and additional unpublished data or studies were excluded.

\section{Selection Criteria}

All RCTs that compared fresh or short-term with older, longterm, or standard RBC transfusion and reported death as an outcome in critically ill adults were included. Inclusion criteria were as follows: (1) anemia present after ICU admission with a requirement for transfusion, (2) comparison of fresh or short-term with older, long-term, or standard RBC transfusion, and (3) reported outcomes of in-ICU mortality, in-hospital mortality, 28/30-day mortality, or 90-day mortality. Exclusion criteria were as follows: (1) the study included duplicate data, (2) the trial did not show death as an outcome, (3) the trial did not contain adequate data for inclusion, (4) the study did not meet the inclusion criteria, and (5) neonates and children in the ICU.

An appropriate methodology of RCT design was defined as the whole methodological design of RCTs, including the following: (1) random sequence generation (selection bias), (2) allocation concealment (selection bias), (3) blinding of participants and personnel (performance bias), (4) blinding of outcome assessment (detection bias), (5) incomplete outcome data (attrition bias), (6) selective reporting (reporting bias), and (7) other bias.

\section{Collection and Analysis of Data}

In this meta-analysis, in-ICU mortality was the primary outcome in critically ill patients with fresh RBC or standard transfusion. From the eligible trials, we abstracted and collected data, including the first author, published year, country, sample size, participants' baseline characteristics, Acute Physiology and Chronic Health Evaluation (APACHE) score, methods, interventions, and outcomes.

\section{Endpoints}

The primary outcome of this study was in-ICU mortality at any time point. The secondary outcomes were in-hospital mortality, 28/30-day mortality, and 90-day mortality.

\section{Statistical Analyses}

We calculated risk ratios (RRs) for dichotomous variables, with 95\% confidence intervals (CIs). All statistical tests were two-sided and $p<0.05$ was considered statistically significant. We estimated heterogeneity using the $\chi^{2}$ and $I^{2}$ tests among studies. All statistical analyses were performed using RevMan version 5.3 (Nordic Cochrane Centre, Copenhagen, Denmark).

\section{Results}

\section{Sample Characteristics}

Using Medical Subject Headings (MeSH) terms, 1,141 potentially eligible records from a search of reviews, systematic reviews, and meta-analyses were identified (Fig. 1). After deletion of duplicate records, 1,020 records 
Fig 1. Literature Search and Screening Process

Trials From Systematic Reviews or Meta-analyses

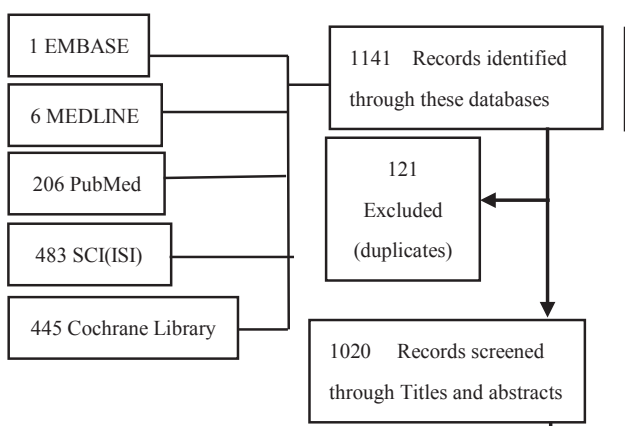

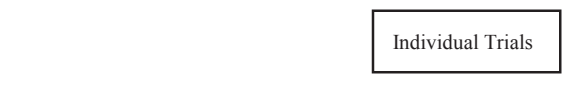

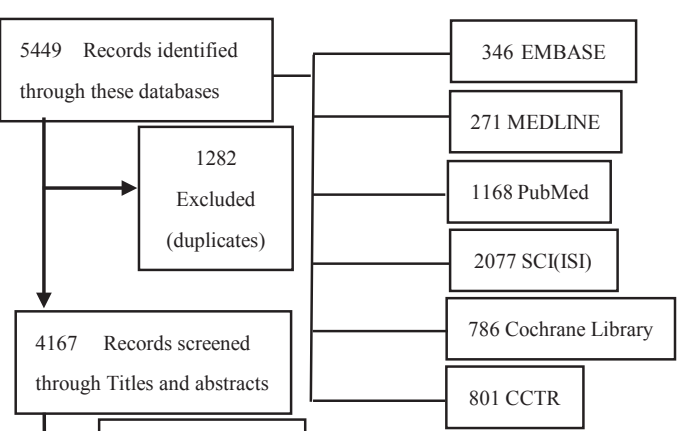

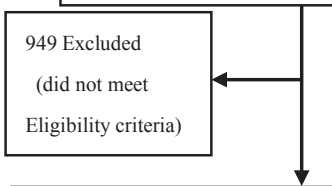

72 Records considered potentially

eligible and full text reviewed
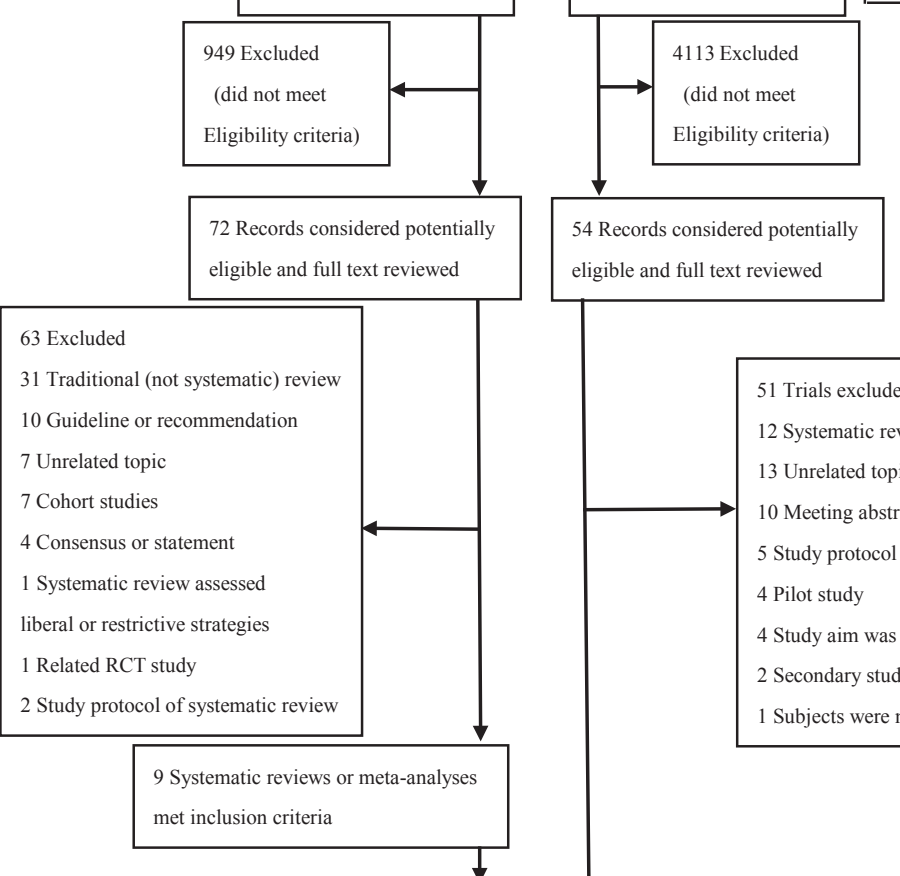

eligible and full text reviewed

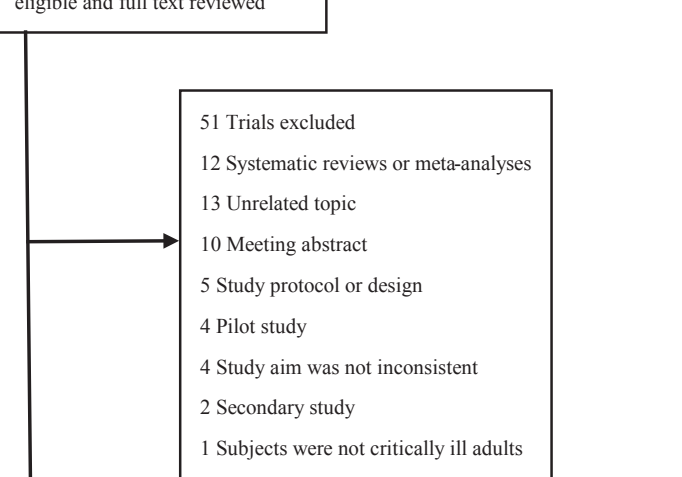

23 Trials (included in 12 systematic reviews or meta-analyses) considered potentially eligible

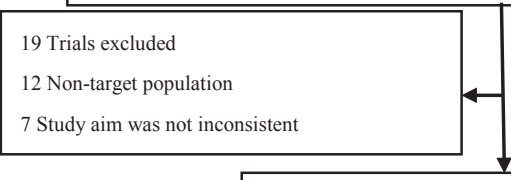

4 Trials met eligibility criteria

3 Trials met eligibility criteria

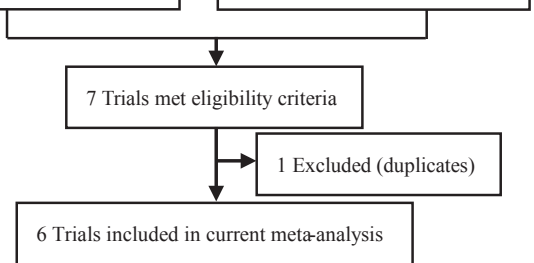

Fig. 1. Literature search and screening process. 
Table 1. Characteristics of included randomized clinical trials

\begin{tabular}{|c|c|c|c|c|c|c|c|c|c|}
\hline \multirow[t]{2}{*}{ Study name } & \multirow[t]{2}{*}{ Country conducted } & \multicolumn{2}{|l|}{ Sample size } & \multicolumn{2}{|l|}{ Age, years } & \multicolumn{2}{|l|}{ Male, $n(\%)$} & \multicolumn{2}{|c|}{ APACHE score ${ }^{\dagger \ddagger}$} \\
\hline & & $\begin{array}{l}\text { fresh/ } \\
\text { short-term }\end{array}$ & $\begin{array}{l}\text { older/ } \\
\text { long-term/ } \\
\text { standard }\end{array}$ & $\begin{array}{l}\text { fresh/ } \\
\text { short-term }\end{array}$ & $\begin{array}{l}\text { older/ } \\
\text { long-term/ } \\
\text { standard }\end{array}$ & $\begin{array}{l}\text { fresh/ } \\
\text { short-term }\end{array}$ & $\begin{array}{l}\text { older/ } \\
\text { long-term/ } \\
\text { standard }\end{array}$ & $\begin{array}{l}\text { fresh/ } \\
\text { short-term }\end{array}$ & $\begin{array}{l}\text { older/ } \\
\text { long-term/ } \\
\text { standard }\end{array}$ \\
\hline Aubron, 2011 & Australia & 25 & 26 & $62 \pm 19$ & $66 \pm 19$ & $20(80)$ & $12(46)$ & $67.1 \pm 30.1^{\ddagger}$ & $55.3 \pm 18.3^{\ddagger}$ \\
\hline Cooper, 2017 & $\begin{array}{l}\text { Australia, New Zealand, Ireland, } \\
\text { Finland, Saudi Arabia }\end{array}$ & 2,457 & 2,462 & $62.5 \pm 16.8$ & $61.4 \pm 17.3$ & $1,311(53.4)$ & $1,258(51.1)$ & $72.6 \pm 29.2^{\ddagger}$ & $73.2 \pm 29.6^{\ddagger}$ \\
\hline Hebert, 2005 & Canada & 26 & 31 & $68.3 \pm 8.5$ & $63.3 \pm 15.3$ & $15(58)$ & $15(48)$ & I & I \\
\hline Heddle, 2012 & Canada & 309 & 601 & $72(60-78)$ & $70(59-78)$ & $171(55.3)$ & $327(54.4)$ & 1 & 1 \\
\hline Kor, 2012 & USA & 50 & 50 & $65(47-73)$ & $65(52-72)$ & $28(56)$ & $29(58)$ & $82(64-108)^{\ddagger}$ & $82(71-112)^{\ddagger}$ \\
\hline \multirow[t]{2}{*}{ Lacroix, 2015} & Canada and Europe & 1,211 & 1,219 & $61.3 \pm 16.7$ & $61 \pm 16.7$ & $682(56.6)$ & $643(53.3)$ & $21.9 \pm 7.7^{\dagger}$ & $21.6 \pm 7.6^{\dagger}$ \\
\hline & \multicolumn{3}{|l|}{ Methods } & \multicolumn{6}{|c|}{ Interventions (fresh/short-term vs. older/long-term/standard stored blood) } \\
\hline Aubron, 2011 & \multicolumn{3}{|c|}{ Multicenter, feasibility pilot, ICU admitted, critically ill patients } & \multicolumn{6}{|c|}{$\begin{array}{l}\text { Randomized to fresher blood (freshest available) vs. older stored blood (oldest available), units were leukocyte- } \\
\text { reduced }\end{array}$} \\
\hline Cooper, 2017 & \multicolumn{3}{|c|}{ Multicenter, critically ill, ICU patients in 59 hospitals } & \multicolumn{6}{|c|}{ Randomized to either the freshest available or the oldest available, leukocyte-reduced } \\
\hline Hebert, 2005 & \multicolumn{3}{|c|}{$\begin{array}{l}\text { Multicenter, pilot study of patients admitted to ICU at } 1 \text { of } 4 \\
\text { Canadian hospitals }\end{array}$} & \multicolumn{6}{|c|}{$\begin{array}{l}\text { Randomized to either RBCs stored for }<8 \text { days or standard issue RBCs based on standard blood bank procedure, } \\
\text { leukocyte-reduced }\end{array}$} \\
\hline Heddle, 2012 & \multicolumn{3}{|c|}{$\begin{array}{l}\text { Single-center pilot trial, consecutive patients admitted to an } \\
\text { academic acute care hospital }\end{array}$} & \multicolumn{6}{|c|}{ Randomized to either the freshest available or standard issue, leukocyte-reduced } \\
\hline Kor, 2012 & \multicolumn{3}{|c|}{$\begin{array}{l}\text { Single-center, medical or surgical patients admitted to an ICU at } \\
\text { Mayo clinic }\end{array}$} & \multicolumn{6}{|c|}{ Randomized to either fresh arm (blood $\leq 5$ days of storage) or standard issue, leukocyte-reduced } \\
\hline Lacroix, 2015 & \multicolumn{3}{|c|}{ Multicenter, critically ill, ICU patients in 64 hospitals } & \multicolumn{6}{|c|}{ Randomized to $\mathrm{RBC}$ units stored for $\leq 8$ days or to $\mathrm{RBC}$ units that were standard issue, units were leukocyte-reduced } \\
\hline
\end{tabular}

Scores on the Acute Physiology and Chronic Health Evaluation II (APACHE II) range from 0 to 71, with higher scores indicating a higher risk of death. ${ }^{\ddagger}$ APACHE III scores range from 0 to 299 , with higher scores indicating a higher probability of death.

remained. Among them, titles and abstracts were screened for inclusion. A total of 72 records were read and nine systematic reviews or meta-analyses met the inclusion criteria. A total of 63 records were excluded for including a traditional (not systematic) review, guideline, or recommendation, an unrelated topic, cohort studies, and a consensus, statement, or study protocol of a systematic review. Finally, four studies that compared fresh or shortterm versus older, long-term, or standard RBC transfusion in ICU patients were included in the study. Additional searches of published RCTs identified 5,449 records. Fifty-four records that were considered appeared to meet the inclusion criteria and the full text was reviewed. However, 51 RCTs were excluded because of a meeting abstract, study protocol or design, pilot study, secondary study, systematic review or meta-analysis, subjects not being critically ill adults, or the study aim being inconsistent with our study. Finally, three RCTs were included in the study. A total of six trials of seven studies were included in the final analysis [19-21, 24-26], and one study was duplicate.

Table 1 shows the baseline characteristics of these trials. The six studies involved 8,467 critically ill adults. Among them, 4,078 patients were assigned to receive fresh or short-term RBCs and 4,389 patients were transfused with older, long-term, or standard RBCs. Three studies were pilot trials of RCTs [24-26]. The mean age of patients in the six trials was more than 60 years. Among the available data of the APACHE score in four studies, three studies showed an APACHE III score [19, 20, 25] and one showed an APACHE II score [21]. All of these studies showed higher scores and a higher risk of death in these patients. Treatment and control group interven- tions are also shown in Table 1. The definition of fresh and standard RBCs varied among the studies. The six trials included in this study all compared fresh and standard blood transfusions. We considered that standard, older, and long-term blood were the same because the blood bank delivers the oldest blood, namely standard RBCs, according to the "oldest unit, first out" policy without special requirements [9].

\section{Mortality}

Mortality was the only variable in our study (Fig. 2). In-ICU mortality occurred in 328 of 1,240 (26.5\%) patients who received fresh transfusion and in 297 of 1,248 (23.8\%) patients who received standard RBCs (RR 1.11, $95 \%$ CI $\left.0.97,1.27, p=0.14, I^{2}=0 \%\right)$. A total of 413 of 1,263 $(32.7 \%)$ patients with transfusion of fresh blood and 391 of $1,268(30.8 \%)$ patients with transfusion of older blood died in hospital (RR 1.06, 95\% CI 0.94, 1.19, $p=0.34, I^{2}=$ $10 \%)$. Twenty-eight/30-day mortality occurred in 869 of $3,747(26.5 \%)$ patients in the fresh arm and in 841 of 3,768 $(23.8 \%)$ in the standard arm (RR 1.04, 95\% CI 0.96, 1.13, $\left.p=0.36, I^{2}=0 \%\right)$. Ninety-day mortality was $28.8 \%$ in the fresh arm $(1,063 / 3,694)$ and $27.7 \%$ in the standard arm $(1,028 / 3,712)\left(\mathrm{RR} 1.04,95 \%\right.$ CI $0.97,1.12, p=0.30, I^{2}=$ $0 \%)$. These findings showed that there were no significant differences in in-ICU, in-hospital, 28/30-day, and 90-day mortality among the types of transfusion.

\section{Risk of Bias}

Figure 3 shows an evaluation of the risk of bias. All of the trials were randomized and double-blind. The six included studies described an explicit generation process of a random sequence and the methods that were 
Fig 2-1 Fresh/Shorterm Blood vs Older/Longterm/Standard Blood for ICU-mortality

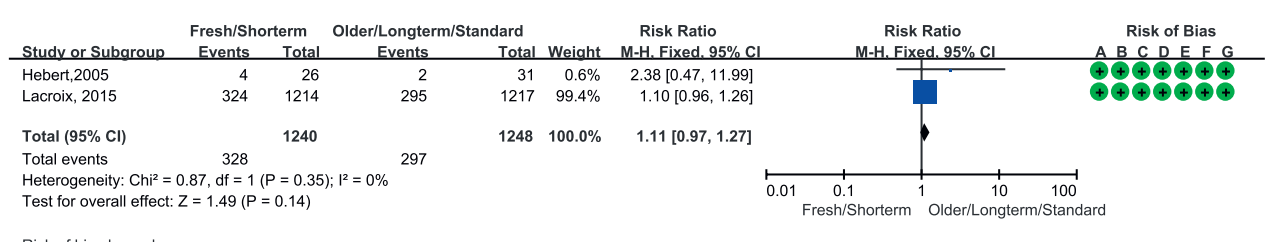

Risk of bias legend

(A) Random sequence generation (selection bias)

(B) Allocation concealment (selection bias)

(C) Blinding of participants and personnel (performance bias)

(D) Blinding of outcome assessment (detection bias)

(E) Incomplete outcome data (attrition bias)

(F) Selective reporting (reporting bias)

G) Other bias

Fig 2-2 Fresh/Shorterm Blood vs Older/Longterm/Standard Blood for in-hospital mortality

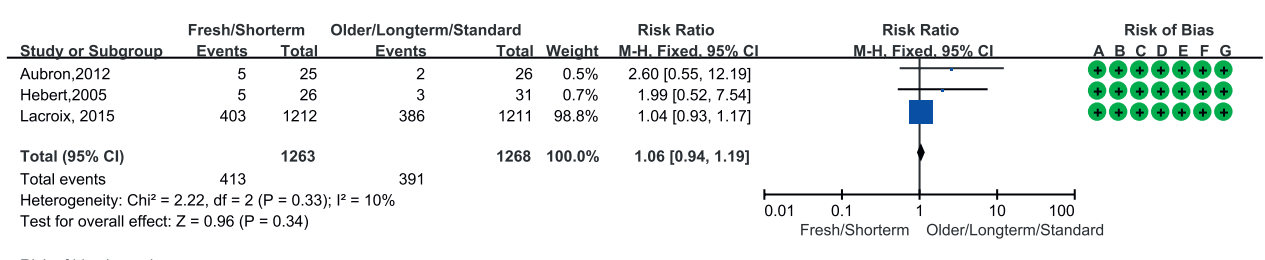

Bisk of bias legend

(A) Random sequence generation (selection bias)

(B) Allocation concealment (selection bias)

(C) Blinding of participants and personnel (performance bias)

(D) Blinding of outcome assessment (detection bias)

(E) Incomplete outcome data (attrition bias)

(G) Other bias

Fig 2-3 Fresh/Shorterm Blood vs Older/Longterm/Standard Blood for 28/30-day mortality

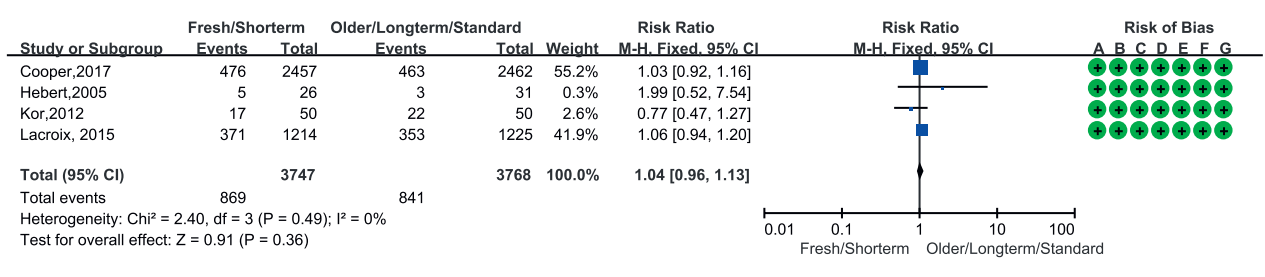

Risk of bias legend

(A) Random sequence generation (selection bias)

(B) Allocation concealment (selection bias)

(C) Blinding of participants and personnel (performance bias)

(D) Blinding of outcome assessment (detection bias)

(E) Incomplete outcome data (attrition bias)

(F) Selective reporting (reporting blas)

Fig 2-4 Fresh/Shorterm Blood vs Older/Longterm/Standard Blood for 90-day mortality

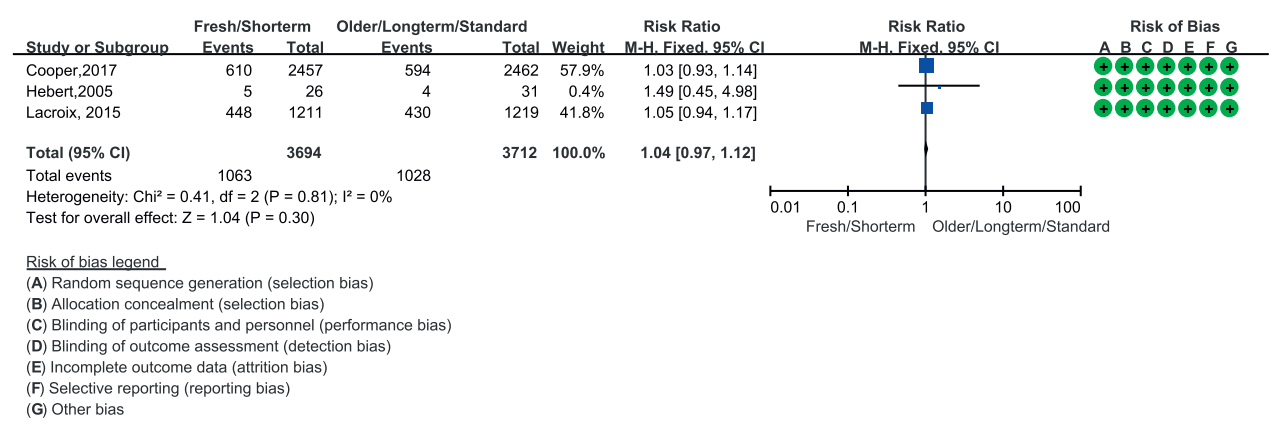

Fig. 2. Fresh/short-term blood versus older/long-term/standard blood for ICU mortality, in-hospital mortality, 28/30-day mortality, and 90-day mortality. 
Fig 3-1. Risk of bias graph.

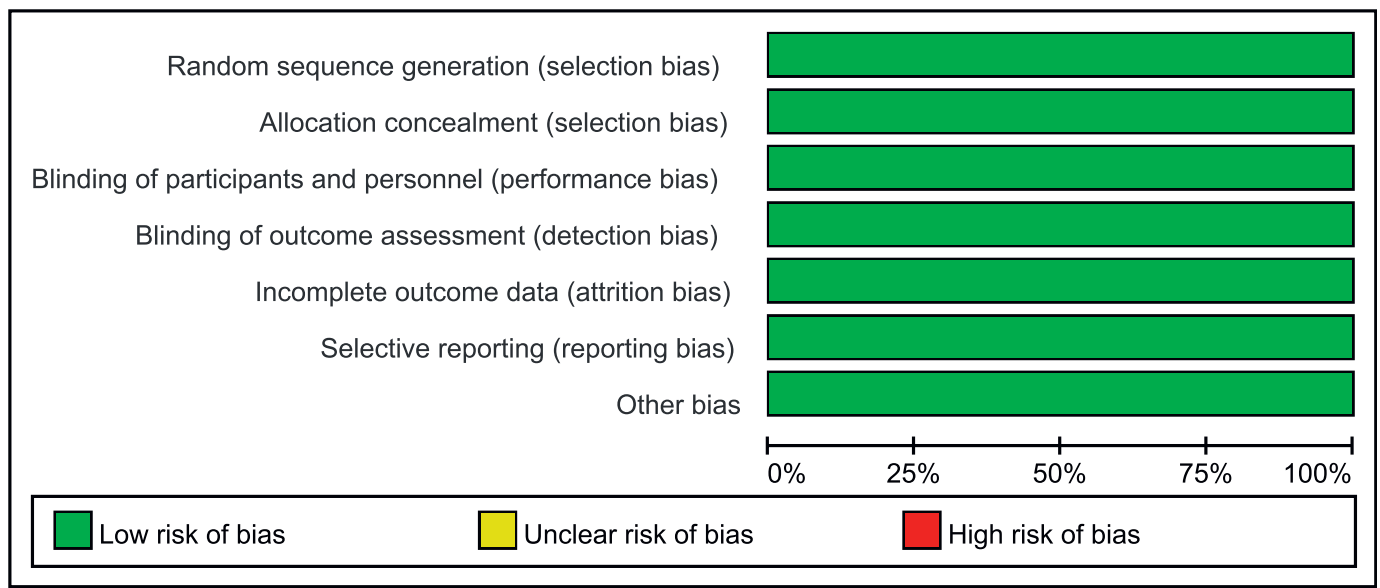

According to the review authors' judgements about each risk of bias item presented as percentages across all included studies

Fig 3-2. Risk of bias summary

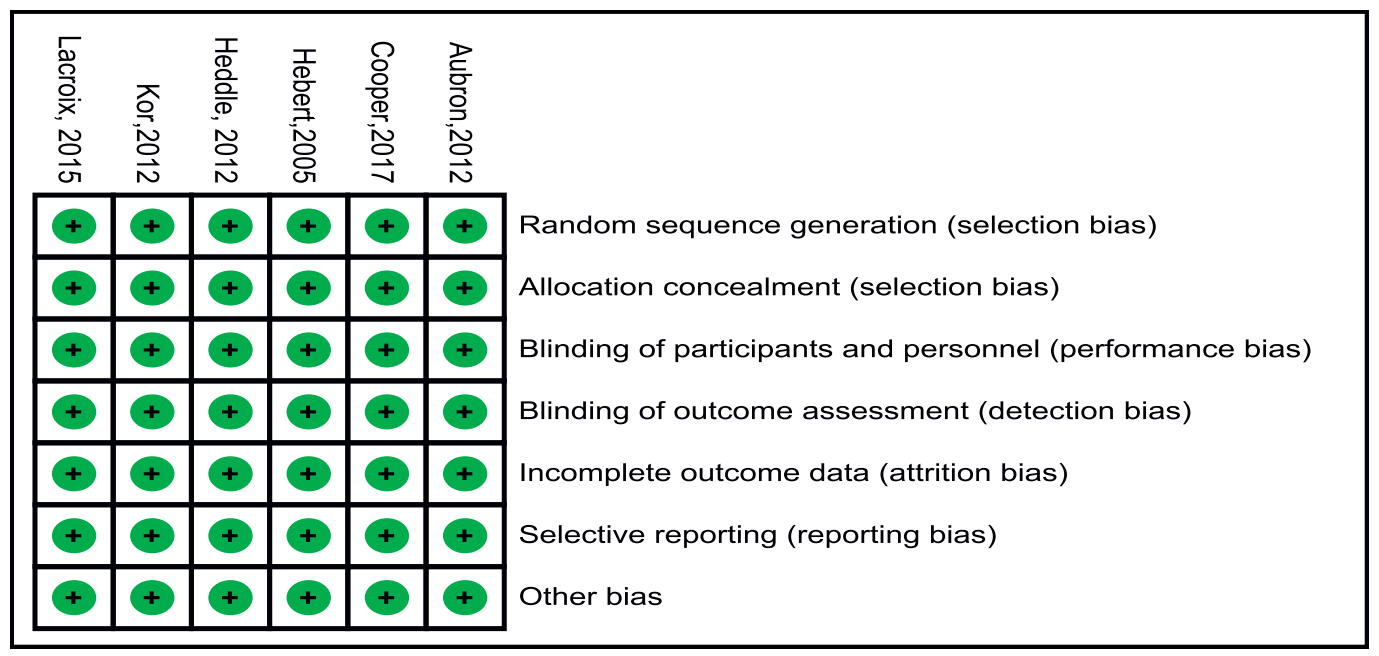

According to the review authors' judgements about each risk of bias item for each included study

Fig. 3. Risk of bias graph and summary.

applied to allocation concealment. We did not report publication bias because the number of trials was less than 10. All of the trials were estimated to have a low risk of bias.

\section{Discussion}

This meta-analysis produced point estimates that were negative in the six trials on mortality of patients with transfusion of fresh or short-term and older, longterm, or standard RBCs in critically ill patients. This con- clusion is consistent with previous reports. Fergusson and colleagues [27] showed that fresh blood transfusion did not improve the mortality rate compared with standard blood transfusion in critically ill premature infants. Karam and colleagues [28] investigated critically ill children who received old RBCs compared with those who received fresh RBCs. They found no significant difference in the mortality rate ( $6.3 \%$ vs. $4.3 \%, p=0.6)$. The CIs around the estimate of mortality were too wide in the six studies to provide valid power to detect a statistical difference. Our study only focused on critically ill adults, regardless of the categories of diseases, and mortality is 
the unique measurement. Our study suggests that fresh or short-term RBC transfusion does not reduce mortality compared with older, long-term, or standard RBCs transfusion in critically ill adults. Accordingly, we support the current blood transfusion strategy in critically ill patients.

\section{Strengths of Our Meta-Analysis}

Our meta-analysis has three main strengths. First, all of the eligible studies were RCTs and only a single variable (mortality) was selected and used in the meta-analysis. To a certain extent, our analysis precluded confounding factors from other variables. Second, our target population mainly focused on critically ill adults. Therefore, our results had a certain reference value for blood transfusion in the ICU. Finally, the variable of mortality is easy to measure during follow-up in patients after fresh or standard blood transfusion. This decreases the risk of dropout from an RCT.

\section{Limitations of Our Meta-Analysis}

This meta-analysis had four main limitations. First, the sample size of mortality in RCTs that compared fresh or short-term RBC transfusion with older, long-term, or standard RBCs transfusion was relatively small. Therefore, the statistical power of the results was limited. Second, the definition of fresh and standard RBCs was not uniform in the six studies. Investigators adopted various cutoff points to define fresh and standard blood that would have affected the conclusions reached. Third, the quality of the RCTs (including random sequence generation, allocation concealment, blinding of participants/ personnel/outcome assessment) was suboptimal. Fourth, the target population in our meta-analysis was critically ill adults, and we excluded infants in the ICU and hospitalized patients.

\section{Generalizability of Our Results}

Although our meta-analysis has the limitations mentioned above, our results indicate that the age of RBCs

na) for her help with the search strategy, literature search, and methodologic guidance for the data analyses. Finally, we thank Ellen Knapp, PhD, from Liwen Bianji, Edanz Group China (www. liwenbianji.cn/ac), for editing the English text of a draft of the manuscript.

\section{Statement of Ethics}

Review and consent of the ethics committee were not required for the research due to the fact that the participants came from the published studies. Informed consent of included patients was not needed for publication due to the fact that this research is a metaanalysis of RCTs. In the study, the data were available due to the fact that all of them came from the published RCTs.

\section{Disclosure Statement}

The authors declare that they have no competing interests.

\section{Funding Sources}

The study was supported by Zunyi Medical College 2017 Academic New Seedling Cultivation and Innovative Exploration Fund (Funding Number: Qian Ke He Platform Talents (2017) 5733-019).

\section{Author Contributions}

Wei Zhang had full access to all of the data in the present study and accepts responsibility for data management and the accuracy of data analyses. Study concept and design: Wei Zhang and Kun Yu. Acquisition, analyses, and interpretation of data: Wei Zhang, Kun $\mathrm{Yu}$, and Ni Chen. Drafting of the manuscript: Wei Zhang and Kun Yu. Critical revision of the manuscript for important intellectual content: Wei Zhang and Miao Chen. Administrative, technical, or material support: Wei Zhang and Ni Chen. Study supervision: Wei Zhang and Miao Chen. All authors agreed to submission of the final version of the manuscript. Wei Zhang is the study guarantor. does not affect mortality after transfusion in critically ill adults.

\section{Conclusions}

The study concluded that age of red cells for transfusion did not affect the outcomes in critically ill patients.

\section{Acknowledgments}

We thank the investigators and patients of all the RCTs contained in this meta-analysis for providing the data and Li Ling (assistant researcher at the Chinese Cochrane Centre, Chengdu, Chi-

\section{References}

1 Corwin HL, Gettinger A, Pearl RG, Fink MP, Levy MM, Abraham E, et al. The CRIT Study: anemia and blood transfusion in the critically ill-current clinical practice in the United States. Crit Care Med. 2004 Jan;32(1):39-52.

2 Prittie JE. Controversies related to red blood cell transfusion in critically ill patients. J Vet Emerg Crit Care (San Antonio). 2010 Apr 1; 20(2):167-76.

3 von Ahsen N, Müller C, Serke S, Frei U, Eckardt KU. Important role of nondiagnostic blood loss and blunted erythropoietic response in the anemia of medical intensive care patients. Crit Care Med. 1999 Dec;27(12): 2630-9.

4 Rodriguez RM, Corwin HL, Gettinger A, Corwin MJ, Gubler D, Pearl RG. Nutritional deficiencies and blunted erythropoietin response as causes of the anemia of critical illness. J Crit Care. 2001 Mar;16(1):36-41. 
5 Lelubre C, Vincent JL. Red blood cell transfusion in the critically ill patient. Ann Intensive Care. 2011 Oct;1(1):43.

6 Vincent JL, Baron JF, Reinhart K, Gattinoni L, Thijs L, Webb A, et al.; ABC (Anemia and Blood Transfusion in Critical Care) Investigators. Anemia and blood transfusion in critically ill patients. JAMA. 2002 Sep;288(12): 1499-507.

7 Alexander PE, Barty R, Fei Y, Vandvik PO, Pai $\mathrm{M}$, Siemieniuk RA, et al. Transfusion of fresher vs older red blood cells in hospitalized patients: a systematic review and meta-analysis. Blood. 2016 Jan;127(4):400-10

8 Lacroix J, Hébert P, Fergusson D, Tinmouth A, Blajchman MA, Callum J, et al.; ABLE study group. The Age of Blood Evaluation (ABLE) randomized controlled trial: study design. Transfus Med Rev. 2011 Jul;25(3): 197-205.

9 Stanger SH, Yates N, Wilding R, Cotton S. Blood inventory management: hospital best practice. Transfus Med Rev. 2012 Apr;26(2): 153-63.

10 Aubron C, Nichol A, Cooper DJ, Bellomo R. Age of red blood cells and transfusion in critically ill patients. Ann Intensive Care. 2013 Jan;3(1):2.

11 Hess JR. Red cell changes during storage. Transfus Apher Sci. 2010 Aug;43(1):51-9.

12 van de Watering L. Red cell storage and prognosis. Vox Sang. 2011 Jan;100(1):36-45.

13 Bennett-Guerrero E, Veldman TH, Doctor A, Telen MJ, Ortel TL, Reid TS, et al. Evolution of adverse changes in stored RBCs. Proc Natl Acad Sci USA. 2007 Oct;104(43): 17063-8.

14 Koch CG, Li L, Sessler DI, Figueroa P, Hoeltge GA, Mihaljevic T, et al. Duration of red-cell storage and complications after cardiac surgery. N Engl J Med. 2008 Mar;358(12):122939

15 Wang D, Sun J, Solomon SB, Klein HG, Natanson C. Transfusion of older stored blood and risk of death: a meta-analysis. Transfusion. 2012 Jun;52(6):1184-95

$16 \mathrm{Hu} \mathrm{H}$, Xenocostas A, Chin-Yee N, Lu X, Chin-Yee I, Feng Q. Transfusion of fresh but not old stored blood reduces infarct size and improves cardiac function after acute myocardial infarction in anemic rats*. Crit Care Med. 2012 Mar;40(3):740-6.

17 Kaukonen KM, Vaara ST, Pettilä V, Bellomo R, Tuimala J, Cooper DJ, et al.; FINNAKI study group. Age of red blood cells and outcome in acute kidney injury. Crit Care. 2013 Oct;17(5):R222.

18 Pettilä V, Westbrook AJ, Nichol AD, Bailey MJ, Wood EM, Syres G, et al.; Blood Observational Study Investigators for ANZICS Clinical Trials Group. Age of red blood cells and mortality in the critically ill. Crit Care. 2011; 15(2):R116.

19 Kor DJ, Kashyap R, Weiskopf RB, Wilson GA, van Buskirk CM, Winters JL, et al. Fresh red blood cell transfusion and short-term pulmonary, immunologic, and coagulation status: a randomized clinical trial. Am J Respir Crit Care Med. 2012 Apr;185(8):842-50.

20 Cooper DJ, McQuilten ZK, Nichol A, Ady B, Aubron C, Bailey M, et al.; TRANSFUSE Investigators and the Australian and New Zealand Intensive Care Society Clinical Trials Group. Age of Red Cells for Transfusion and Outcomes in Critically Ill Adults. N Engl J Med. 2017 Nov;377(19):1858-67.

21 Lacroix J, Hébert PC, Fergusson DA, Tinmouth A, Cook DJ, Marshall JC, et al.; ABLE
Investigators; Canadian Critical Care Trials Group. Age of transfused blood in critically ill adults. N Engl J Med. 2015 Apr;372(15): 1410-8.

22 Chai-Adisaksopha C, Alexander PE, Guyatt G, Crowther MA, Heddle NM, Devereaux PJ et al. Mortality outcomes in patients transfused with fresher versus older red blood cells: a meta-analysis. Vox Sang. 2017 Apr;112(3): 268-78.

23 Dessertaine G, et al. [Does red blood cell storage time still influence ICU survival?]. Transfus Clin Biol. 2008 Sep;15(4):154-9.

24 Heddle NM, Cook RJ, Arnold DM, Crowther MA, Warkentin TE, Webert KE, et al. The effect of blood storage duration on in-hospital mortality: a randomized controlled pilot feasibility trial. Transfusion. 2012 Jun;52(6): 1203-12.

25 Aubron C, Syres G, Nichol A, Bailey M, Board J, Magrin G, et al. A pilot feasibility trial of allocation of freshest available red blood cells versus standard care in critically ill patients. Transfusion. 2012 Jun;52(6):1196-202.

26 Hebert PC, et al. A pilot trial evaluating the clinical effects of prolonged storage of red cells. Anesth Analg. 2005 May;100(5):1433-8.

27 Fergusson DA, Hébert P, Hogan DL, LeBel L, Rouvinez-Bouali N, Smyth JA, et al. Effect of fresh red blood cell transfusions on clinical outcomes in premature, very low-birthweight infants: the ARIPI randomized trial. JAMA. 2012 Oct;308(14):1443-51.

28 Karam O, Tucci M, Bateman ST, Ducruet T, Spinella PC, Randolph AG, et al. Association between length of storage of red blood cell units and outcome of critically ill children: a prospective observational study. Crit Care. 2010;14(2):R57. 